\title{
Mensuração de ativos biológicos pelo método de custo histórico e valor justo na pecuária leiteira
}

Mesure actifs biologiques selon la methode de cout historique et la juste valeur des betail lait

\section{Biological assets measurement by method of historical cost and fair value in livestock milk} Medida de activos biológicos por el método de costo histórico y valor justo en la
ganadería lechera

\author{
Eloir Trindade Vasques Vieira* \\ (eloir@ucdb.br) \\ Luis Carlos Vinhas Itavo** \\ (luis.itavo@ufms.br) \\ Jose Aparecido Moura Aranha** \\ (jaranha@terra.com.br)
}

Recebido em 13/10/2015, revisado e aprovado em 12/11/2015; aceito em 23/11/2015

DOI: http:/ / dx.doi.org/10.20435/1518-70122016114

\begin{abstract}
Resumo: Na pecuária leiteira, a mensuração pelo custo histórico se faz pelo registro de todos os custos ocorridos no período, tais como gastos com insumos, manejo, salários, ou aquilo que se pode chamar de gastos operacionais. Ocorre que há ressalvas quanto a essa mensuração. Assim, surgiu a mensuração contábil pelo valor justo (fair value), sugerida por órgãos reguladores em todo o mundo, pois possibilita segundo autores, credibilidade nas informações.
\end{abstract}

Palavras-chave: Ativo biológico. Custo histórico. Valor Justo.

Abstract: In dairy farming, measurement, at historical cost, it is the registration of all costs incurred in the period, such as spending on inputs, management, salaries, or can be called operating expenses. It turns out that there are shortcomings with regard to this measure. So did the accounting measurement at fair value (fair value), suggested by regulators around the world because it enables according to authors, credibility of the information .

Key words: Biological assets. Cost history. Fair value.

Résumé : Dans l' élevage laitier, la mesurage par le coût historique se fait par l'enregistrement de tous les coûts produits dans la période, tels que les frais et dépenses en intrants, la gestion, les salaires, qu'on peut appeler de frais d'exploitation. Toutefois, existe quelques réserves avec cette mesurage. Ainsi, est apparu la mesurage comptable à la juste valeur (fair value) suggéré par les organismes régulateurs dans tout le monde, car elle permet selon les auteurs, la crédibilité des 'informations.

Mots-clés: Actif biologique. Le coût historique. Juste valeur.

Resumen: En la ganadería lechera, la medida, por el costo histórico, se hace por el registro de todos los costos del período, como los gastos con factores de producción, gestión, salarios, que también se pueden llamar gastos de operación. Sin embargo, hay otras posibilidades. Así, surgió la medición contable por el valor justo (fair value), sugerido por los órganos reguladores de todo el mundo, ya que permite, según los autores, credibilidad en las informaciones.

Palabras clave: Activo biológico. Costo histórico. Valor justo.

\section{INTRODUÇÃO}

Bibliografias e pesquisas a campo apontam que, em atividades rurais, a mensuração dos ativos biológicos há tempos vem sendo efetuada somente pelo custo histórico. Nesse custo, precisam ser mensuradas e anotadas todas as etapas de custos, desde o nascimento do animal, despesas de manejo, até sua comercialização. Ocorre que tal método requer, além do controle preciso desses fatos, não acompanhar, segundo alguns autores, a sazonalidade do mercado, tais como as mudanças ocasionais de preços, pois são computados ao custo do período de compra.

\footnotetext{
* Universidade Católica Dom Bosco (UCDB), Campo Grande, MS, Brasil.

** Universidade Federal de Mato Grosso do Sul (UFMS), Campo Grande, MS, Brasil.
} 
Dessa forma, com as adequações das normas contábeis aos padrões internacionais de contabilidade, surgiu uma nova possibilidade de mensuração desses ativos biológicos, a qual já existe em outros países; surge, então, o valor justo dos ativos biológicos e produtos agrícolas apresentados também como medida de avaliação. Essa medida considera o valor de mercado.

O Comitê de Pronunciamento Contábil (CPC 29) especifica "ativo biológico é um animal ou plantas vivos" e "produção agrícola é o produto colhido de ativo biológico da entidade". Em nosso caso específico, o ativo biológico é o animal, o gado leiteiro, e o produto agrícola, o leite.

O objetivo geral deste trabalho é apresentar as peculiaridades da aplicação destes dois métodos de mensuração: custo histórico e valor justo dos ativos biológicos. Esta pesquisa se caracteriza como descritiva. O estudo foi realizado com levantamento bibliográfico e documental, apresentando os dois métodos de mensuração: custo histórico e valor justo.

Dessa forma, busca-se auxiliar o produtor rural na apresentação dos resultados de sua atividade, auxiliando também em sua tomada de decisão sobre investimentos futuros na atividade rural.

\section{EMPRESA RURAL}

São vários os autores que conceituam a palavra empresa, todos, a sua maneira, retratam a importância de análise por parte dos gestores quanto ao fim desta, e que ela deve ser pensada separadamente: pessoa física, o dono; e pessoa jurídica, a empresa.

Os autores Crepaldi (2006) e Franco (1999) tratam a empresa como uma associação de pessoas, entidade que trabalha a exploração de uma determina atividade econômica. Já Cassaro (1999) retrata a empresa como atividade jurídica com a obrigação de apresentar lucro, bem como deve atender as necessidades de seus sócios. Harrington (1997) faz uma reflexão de que, a cada dia, os empresários precisam inovar criando novos modelos funcionais, pois, para este autor, os modelos tradicionais não são mais eficazes.

A propriedade rural também entra nesse contexto de empresa. Em muitas propriedades, este inclusive é um dos grandes desafios, que o produtor rural entenda que a fazenda, a criação não é propriedade da família, e sim propriedade da empresa, que precisa ser gerida com imparcialidade, anotando todas as informações e ocorrências para que se obtenha, ao final de um determinado período, o resultado das ações, seja do resultado do plantio, ou o resultado da venda do ativo ou do bem produzido pelo ativo.

Dessa forma, a pequena empresa rural é concebida com a especificidade de ser gerida pelo seu proprietário, geralmente possui poucos funcionários, pequenas despesas e conhecimento limitado de tecnologia. Verifica-se, também, a gestão diferenciada desses negócios rurais, em que há, por vezes, gestão maciça da figura do proprietário-dirigente, em que muitas vezes o cliente pode até discutir preço, qualidade do produto diretamente com o dono do negócio. Nesses casos, em algumas empresas, se confunde a pessoa física, formada pelo proprietário, e a pessoa jurídica, a formada em si, da empresa.

A Lei $\mathrm{n}^{\circ} 4.504$, de 30 de novembro de 1964, art. $4^{\circ}$, traz a definição de empresa rural:

Empreendimento de pessoa física ou jurídica, pública ou privada, que explore econômica e racionalmente imóvel rural, dentro de condição de rendimento econômico da região em que se situe e que explore área mínima agricultável do imóvel segundo padrões fixados, pública e previamente, pelo Poder Executivo. Para esse fim, equiparam-se às áreas cultivadas, as pastagens, as matas naturais e artificiais e as áreas ocupadas com benfeitorias.

Por menor que seja a produção da empresa rural, a informação que se acumula durante o período é grande, provavelmente, se tornará complexa se não forem registrados e analisados os dados resultantes do sistema de produção. Dessa forma, terra, capital e trabalho juntos propiciam a melhoria da atividade, pois para a agricultura, segundo Crepaldi (2006, p. 26):

A terra - é o fator de produção mais importante, pois na terra se aplicam os capitais e se trabalha para obter a produção;

O capital - representa o conjunto de bens colocados sobre a terra com 
objetivo de aumentar sua produtividade e ainda facilitar e melhorar a qualidade do trabalho humano;

O trabalho - é o conjunto de atividades desempenhadas pelo homem. A tarefa de administrar é também considerada trabalho, assim como lavrar a terra, cuidar de animais, construir cercas etc.

Sendo assim, a atividade agrícola é representada pela atividade de exploração da terra, seja para algum cultivo, criação de animais, para produção ou abate, mas com o objetivo principal de produtos que atendam a necessidade humana de subsistência.

Há discussões também sobre a empresa familiar, e se esta faz parte da cadeia do agronegócio. Nesse sentido, o agronegócio pode ser definido como um conjunto de atividades que, associadas, garantem a produção, a transformação, a distribuição e o consumo dos produtos originários da agropecuária (MAPA, 2013). O Ministério da Agricultura Pecuária e Abastecimento (2013) explica que toda cadeia produtiva da agropecuária, desde o fornecimento dos insumos até a chegada dos produtos à mesa do consumidor, pode ser englobada dentro do agronegócio. O grande desafio da gestão rural é conhecer os custos que envolvem cada atividade produtiva e, dessa forma, contribuir para o planejamento e controle de suas atividades.

Nos anos de 2011 e 2012 devido ao aumento de renda da população brasileira, a utilização do leite no Brasil foi aumentada, sendo que, de acordo com a Companhia Nacional de Abastecimento (CONAB, 2012), por este motivo foi necessária a importação desse produto.

Dessa forma, faz-se necessária a utilização de vantagens competitivas, itens que diferenciam a empresa no mercado, buscando satisfazer as necessidades dos clientes (PORTER, 1989).

Pesquisa desenvolvida pelo Instituto Brasileiro de Geografia e Estatística (IBGE, 2013) reforça que, em países desenvolvidos, o consumo por habitante é de 238 litros/ano e que, no Brasil, é de 170 litros por habitante/ano, menor que a recomendação do Ministério da Saúde, cuja recomendação é de 200 litros/ano.

Segundo Nogueiras (2014, p. 16), "no ano de 2014, o valor da desmama foi $30 \%$ superior ao preço praticado em 2010. A vaca valorizou $24 \%$, e $40 \%$ dos bezerros machos disponíveis nasceram em propriedades da pecuária leiteira".

Essa empresa rural de produção leiteira, mesmo com todos esses dados positivos, necessita ficar atenta a seus indicadores. Assim, a mensuração dos custos pode auxiliar na rentabilidade da unidade produtiva, permitindo extrair resultados mais precisos sobre os custos que envolvem todo o processo de produção dentro e fora da porteira. Dessa forma, a busca do entendimento dos itens contábeis pode ser fator de auxílio a essa gestão.

\section{CONTABILIDADE}

A contabilidade apresenta-se tão antiga quanto a origem do homo sapiens. Alguns historiadores retratam sinais da existência das contas há aproximadamente 4.000 anos a.C. Mesmo os primitivos, ao anotarem nas cavernas alguns riscos simulando contas, ou as primeiras comunidades ao contar os rebanhos, ao efetuarem os escambos, já praticavam uma forma rudimentar de contabilidade (IUDICIBUS, 2000).

Ocorre que, para que se proceda de fato, para Crepaldi (2006, p. 89), uma informação contábil tem que ser "confiável, deve inspirar confiança, a tal ponto que o usuário da informação tenha segurança nas informações fornecidas". Além disso, deve ser ágil, deve respeitar a tempestividade das informações e ser elucidativa. E, por fim, essa contabilidade deve ser uma fonte para tomada de decisões. Dessa maneira, inicia-se o grande desafio do produtor rural, que, por costume ou pelas ferramentas de trabalho, mais voltadas ao campo, não utiliza os controles usualmente em seu cotidiano.

A contabilidade rural pode ser definida como a contabilidade geral aplicada às empresas rurais, auxiliando o proprietário dessa empresa do campo, estudando o patrimônio dessa atividade, buscando a conciliação de seus bens direitos e obrigações (MARION, 2012).

Verifica-se que as particularidades são quanto aos insumos, às atividades, que são agrícolas, mas que não diferenciam dos controles urbanos.

Buscando normatizar os princípios contábeis das companhias abertas, foi criada 
em 1976, A Lei $n^{\circ}$ 6.404, que posteriormente abrangeu a todas as empresas do Brasil. Assim, o que ocorre é que a mesma contabilidade que é lida e interpretada no Nordeste do país, é a mesma da Região Centro-Oeste, por exemplo, os mesmos relatórios entendidos pelos profissionais da contabilidade mas diferente do que ocorre com outros países. Assim, passados muitos anos, buscando harmonizar as Normas Contábeis Brasileiras aos padrões internacionais de contabilidade, mudanças ocorreram com a publicação da Lei $n^{\circ} 11.638$ no ano de 2007 e, posteriormente, com a publicação da Lei no 11.941 no ano de 2009.

Antes de comentarmos sobre a importância da mensuração de valores na contabilidade rural, faz necessário entender o porquê de se ter uma medida de desempenho.

Para Bond (2002), a medida de desempenho tem por finalidade adequar, ajustar, proporcionar, ou regular alguma atividade. Para os autores Miranda e Silva (2002), também pode ser identificada como um conjunto de indicadores e relatórios de que a organização se utiliza para avaliar como determinada empresa tem se comportado no mercado.

As razões principais de investirem em medição de desempenho são controlar as atividades operacionais da empresa, alimentar o sistema a funcionários, controlar o planejamento, criar, implantar e conduzir estratégias competitivas, identificar problemas que necessitem intervenção de gestores, verificar se a missão da empresa está sendo atingida. A preocupação com a sustentabilidade também deve ser uma premissa nas empresas rurais, razão pela qual ela será analisada.

\section{SUSTENTABILIDADE}

São vários os autores que retratam a importância da Sustentabilidade, seja a ambiental, a social, ou a econômica, que é o foco de nosso estudo. Para que se mantenha no mercado, a empresa necessita, ao final de um determinado período, apontar os resultados positivos de sua operação, o que em contabilidade conceitua-se como lucro, quando se tem o resultado das receitas superiores às despesas ocorridas no período.

Elaborado pela Comissão Mundial sobre Meio Ambiente das Nações Unidas, o conhecido Relatório Brundtland define sustentabilidade como: "o desenvolvimento que satisfaz as necessidades atuais sem comprometer a habilidade das futuras gerações em satisfazer suas necessidades" (WCED, 1987).

Assim sugere-se não apenas a busca de geração de lucros, mas também seu alcance com preocupação ambiental. Autores como Viviani (2011, p. 12) associam que sustentabilidade e ecologia andam lado a lado "praticamente sinônimo de desenvolvimento sustentável".

Verifica-se, assim, que a questão social e econômica, não está dissociada da questão ambiental:

A sustentabilidade tem sido descrita como a capacidade de prever as necessidades principais da sociedade de uma forma que possa ser facilmente continuada no futuro indefinido, sem efeitos negativos indesejados. A maioria das definições de sustentabilidade são enquadradas em termos de três objetivos sociais amplos: saúde ambiental, econômica e social ou de bem-estar. (COMISSÃO..., 2010, p. 23).

A preocupação com a otimização da utilização de produtos, insumos, a questão do desperdício, em geral ocasionado por utilização desnecessária, corresponde a fatores que precisam ser verificados. Dessa forma, o grande desafio da contabilidade se faz presente: buscar resultados positivos à empresa, mantendo a continuidade dessa empresa rural, porém com um olhar voltado também à preservação ambiental.

Nesse contexto, outro termo utilizado aplicado à gestão empresarial é a ecoeficiência, o que, para Savitz e Weber (2007, p. 42):

Significa redução da qualidade de
recursos utilizados para a produção
de bens e serviços, aumentando os lu-
cros da empresa e, ao mesmo tempo,
reduzindo seu impacto ambiental. A
temática básica é simples: poluição é
desperdício e desperdício é anátema,
pois significa que a empresa está pa-
gando por algo que não usa. Em face
da clareza desse raciocínio lógico, é
surpreendente que poucas empresas
se empenhem com diligência em
busca da ecoeficiência.

Em vista disso, torna-se necessário apresentar o método de mensuração de ativo 
biológico pelo método de custo histórico, considerado por alguns autores, como de maior aplicabilidade.

\section{MENSURAÇÃO DE ATIVOS BIOLÓGI- COS PELO MÉTODO DE CUSTO HISTÓ- RICO}

Os custos históricos representam o quanto a entidade de fato pagou por um determinado ativo. São, portanto, mensurados, considerados pelo valor pago em sua data de aquisição.

Alguns autores defendem sua utilização pelo fator de serem objetivos. Niyama e Silva $(2008$, p. 131) reportam que "o custo histórico é a base de avaliação mais comum na preparação das demonstrações contábeis".

Especificamente na pecuária, autores como Marion (2002), utilizam a técnica de rateio, a qual "soma-se do custo do rebanho, (salários, alimentação do gado, exaustão de pastagens, depreciação dos reprodutores, cuidados veterinários) e divide-se o resultado pelo total de cabeças do rebanho em formação)".

Para o rateio dos custos indiretos comuns a mais de um produto na atividade de criação de gado, como é o caso da pecuária de cria, recria, engorda, e pecuária leiteira, a contabilidade utiliza o método do custo histórico ou o valor justo (fair value) (MARION, 2002).

De acordo com os autores citados, a objetividade do método é utilizada, sendo considerada o custo do ativo biológico no período. Iudícibus (2004, p. 149) também reforça sua utilização, ao afirmar que:

É sua possível aderência, no momento da aquisição, para expressar os potenciais de serviços futuros, para a empresa, do ativo que está sendo adquirido. Por outro lado, na avaliação dos ativos não monetários, é sua objetividade e verificabilidade o motivo de sua adoção.

Para esses autores, o método mais adequado é o método do ativo biológico, animal ou planta vivo, que mensura no tempo cada custo; nesse caso, custo histórico. Para melhor análise, faz-se necessário também utilizar outro método de análise, qual seja a mensuração pelo valor justo.

\section{MENSURAÇÃO DE ATIVOS BIOLÓGI- COS PELO MÉTODO DE VALOR JUSTO}

A mensuração dos ativos biológicos pelo valor justo já é utilizada em outros países, como é o caso das normas contábeis americanas, mas ganhou maior notoriedade internacionalmente com as mudanças contábeis. Assim, o intuito brasileiro de adequar as normas contábeis brasileiras às normas internacionais de contabilidade.

Herbohn e Herbohn (2006, p. 176-177) retratam que empresas australianas já contabilizam seus ativos biológicos de acordo com a norma Australian Accounting Santandards Board (AASB) 1037. Consideram que Ativos biológicos devem ser mensurados conforme valor de mercado menos os custos de venda.

Em 2001, o Internacional Accounting Standards Comitee (IASC) publicou a International Accounting Standards 41-Agriculture (IAS 41), atendendo ao setor agrícola, fazendo menção ao valor justo como base de mensuração dos ativos biológicos e dos produtos agrícolas (IBRACON, 2009).

Evidencia-se também que, em contraponto a este país, Feleagã et al. (2012) referenciam que, na Romênia, a Norma Internacional IAS 41 não é aplicada nos regulamentos romenos e, para estes autores, os principais inconvenientes se referem a que o custo de reconhecer ativos biológicos, a valor justo, excede os ganhos obtidos por esse método de avaliação, que aumenta a volatividade dos lucros, e selecionam uma taxa de desconto para a avaliação, envolvendo julgamento subjetivo.

Especificamente sobre o assunto ativo biológico, o CPC 29 no Brasil é exigido na elaboração das demonstrações contábeis das companhias de capital aberto desde 2009. Nesse sentido, o CPC 46 conceitua que "ativo biológico é um animal ou planta vivos, e produção agrícola é o produto colhido de ativo biológica da entidade".

Quanto a valor justo, esse CPC o define como:

Valor justo é o preço que seria recebido pela venda de um ativo ou que ser ia pago pela transferência de um passivo em uma transação não forçada entre participantes do mercado na data de mensuração. (CPC 46, 2012).

Vários são os autores que defendem a aplicação do valor justo baseado em pesquisas 
realizadas. Lisboa e Scherer (2000) retratam que o modelo de contabilidade vigente está em aplicação há mais de 100 anos, e que não reflete a realidade. Rech et al. (2006, p. 11) consideram que pelo valor justo "é possível demonstrar de maneira justa e verdadeira a variação patrimonial ocorrida durante determinado período.

Outra concepção que precisa ser desmistificada é a de que o valor justo é o valor de mercado; sua amplitude é maior, pois, quando não há valor disponível, pode ser utilizado o fluxo descontado (CPC 12, 2008; ERNEST\&YOUNG; FIPECAFI, 2010).

A priori a crítica que se faz é que o valor justo pode representar aumento na lucratividade ou discrepância de valores, mas pesquisas empíricas realizadas por autores como Watts (2003), Dowling; Godfrey (2001), comparando estudos ao avaliar os ativos biológicos e os dois critérios, levaram à conclusão de que não aumentam os lucros, receitas, e que inclusive o valor justo apresenta, como ponto positivo, a simplicidade nas informações, quando há claro valores de mercado disponíveis.

A Norma Brasileira de Contabilidade NBC TG 1000 (cosif, s.d.), Contabilidade para Pequena e Média Empresa, faz o reconhecimento pelo valor justo no item 34 .

A entidade deve reconhecer um ativo biológico ou um produto agrícola quando, e apenas quando:

a) a entidade controlar o ativo como resultado de eventos passados;

b) for provável que benefícios econômicos futuros associados com o ativo fluirão para a entidade; e

c) o valor justo ou custo do ativo puder ser mensurado de maneira confiável sem custo ou esforço excessivo.

O CPC 46 (2012) faz referência ao mercado ativo, "Em alguns casos, uma única técnica de avaliação é apropriada (por exemplo, ao avaliar um ativo ou um passivo utilizando preços cotados em mercado ativo para ativos ou passivos idênticos)". Dessa forma, verifica-se que o acesso à informação deve ser fácil, com algumas críticas quando à subjetividade, mas trazendo discussão para o que se entende por valor de mercado, proporcionado pela oferta e demanda, o que críticos ao custo histórico reportam que não ocorre em vista daquela utilização.

Aranha (2015) ressalva que vários são os sites que fornecem cotações, "entretanto os preços oficiais são os disponibilizados pelo Centro de Estudos Avançados em Economia Aplicada - ESALQ/USP, é o parâmetro de preços utilizado pela BM\&FBovespa".

Para fins de mensuração a valor justo, os ativos biológicos podem ser separados em duas categorias distintas: ativos biológicos com mercado ativo e, consequentemente, preços correntes, e ativos biológicos sem mercado ativo, consequentemente, sem preços correntes (RECH, 2011).

Dessa forma, como técnica para determinar o valor justo, o CPC 46, recomenda que:

A entidade deve utilizar técnicas de avaliação que sejam apropriadas nas circunstâncias e para as quais haja dados suficientes disponíveis para mensurar o valor justo, maximizando o uso de dados observáveis relevantes e minimizando o uso de dados não observáveis.

Entretanto nem todos os dados estão disponíveis nem são facilmente observáveis, em que pese aos princípios gerais de que as técnicas de avaliação devem maximizar o uso de dados observáveis relevantes e minimizar o uso de dados não observáveis (CPC 46), mas, em determinadas circunstâncias, essas práticas não são possíveis.

Decorrente da dificuldade de se obter dados observáveis relevantes, o próprio CPC 46 propõe o que se denomina de hierarquia de valor justo. O propósito dessa hierarquia é aumentar a consistência e comparabilidade nas mensurações contábeis a valor justo, bem como nas divulgações correspondentes (CPC 46).

Para o CPC 46 (2012) a hierarquia está disposta em três níveis:

Informações de Nível 1: são os preços cotados (não ajustados) em mercados ativos para ativos ou passivos idênticos a que a entidade possa ter acesso na data de mensuração.

Informações de Nível 2: são informações que são observáveis para o ativo ou passivo, seja direta ou indiretamente, exceto preços cotados incluídos no Nível 1. 
Informações de Nível 3: são dados não observáveis para o ativo ou passivo.

No contexto do CPC 29, é especificado que tal mensuração é obrigatória, desde o ano de 2008, para Empresas de capital aberto que exploram ativos biológicos. Geralmente tais empresas de Sociedade Anônima (S/A) possuem ações negociadas em bolsa.

Preocupação também há quanto à confiabilidade da informação quando não há mercado ativo, dada a preocupação com o julgamento do avaliador.

[...] é importante destacar que a avaliação a valor justo para certos elementos patrimoniais, principalmente os que não possuem um mercado ativo, exige certo grau de julgamento por parte do avaliador, onde pode impactar na confiabilidade dessa informação e, por conseguinte, contrapor a relevância da mesma. (YANG; ROHRBACH; CHEN, 2005).

Para Cobra (1992, p. 468), faz-se necessário que a empresa faça a seguinte análise: "Qual é o valor justo pela posse de um bem ou de um serviço? Qual é o processo mental do indivíduo ao estabelecer uma relação entre preço e utilidade do bem"?

Alguns autores também defendem que, dependendo da utilização, pode ser efetuada a análise de um ou outro método.

[...] a quantidade de medidas diferentes reflete a variedade de aplicações da contabilidade, pois cada aplicação sugere uma medida distinta. Como consequência, embora haja vantagem clara na aceitação geral de um único conceito abrangente, uma análise mais atenta dos padrões de utilização indica que um único conceito de avaliação não seria capaz de atender igualmente bem todas as finalidades. O conceito apropriado, em cada caso, exige que se conheça quem usará a contabilidade e para que fim. (HENDRIKSEN; VAN BREDA, 1999, p. 304).

As verificações de desempenho são importantes para mensurar os objetivos e identificar as decisões a serem tomadas.

Cabe ressaltar que, para o CPC 29, um ativo biológico é um animal e/ou planta, vivos. Entretanto o documento de revisão $n^{\circ} 8$, aprovado em 07 de agosto de 2015 e divulgado em 05 de novembro de 2015, com efeitos na contabilidade das companhias somente a partir do exercício de 2016, incluiu a classificação de ativos biológicos em dois grupos distintos:

a) Ativos biológicos consumíveis - que são aqueles passíveis de serem colhidos como produto agrícola ou vendidos como ativos biológicos como, por exemplo: rebanhos de animais mantidos para a produção de carne ou venda, produção de peixe, plantações de milho, soja, trigo, entre outros.

b) Ativos biológicos para produção - neste caso, os demais tipos como, por exemplo: rebanhos de animais para produção de leite, árvores frutíferas (plantas portadoras) destinadas a produzir frutos, animais para produção de lã e outros similares.

Como se observa, a pecuária bovina leiteira se enquadra como ativo biológico para produção, neste caso o leite, e, para efeitos do CPC 29, deve ser mensurada a valor justo menos a despesa de venda. Quanto ao produto, leite, este também deve inicialmente ser mensurado a valor justo menos a despesa de venda (CPC 29, notas item 2).

A mensuração dos custos pode auxiliar na melhoria da empresa pesquisada, objetivando resultados mais precisos e positivos. Seja por um método ou outro, a contabilidade permite apresentar a seu usuário auxílio à tomada de decisão.

\section{CONSIDERAÇÕES FINAIS}

Verificou-se que a cadeia produtiva leiteira está em expansão, possui mercado no país e tem possibilidades de crescimento. Ocorre que, em muitos casos, a propriedade rural não é considerada pelos proprietários como empresa, e muitos não contabilizam, ou não fazem contabilidade em seus negócios.

Foi apresentado que ativo biológico é todo animal ou planta, no caso específico desta pesquisa, pecuária bovina, o gado, e o produto agrícola, especificamente o leite.

Assim, há anos os ativos biológicos eram mensurados considerando somente o custo histórico, no qual se considerava somente os custos mensurados ao longo do tempo.

Com as alterações da lei $\mathrm{n}^{\circ} 11.638 / 07$ e as adequações das normas contábeis aos padrões internacionais de contabilidade, 
foram emitidos pronunciamentos técnicos designando que, quando há mercado ativo do produto biológico ou produto ativo, e este pode ser utilizado com confiança, poderá ser utilizada a mensuração pelo valor justo, o que vários autores defendem como mais próximo à realidade da propriedade, pois consideram outros fatores, como sazonalidade. Dess a forma, foi apresentada mais de uma possibilidade de mensuração na atividade rural "pecuária leiteira".

\section{REFERÊNCIAS}

ARANHA, José Moura Aranha. Mensuração de ativos biológicos: uma proposta para apropriação de custos com base na unidade animal (UA). 2015. 112f. Dissertação (Doutorado em Ciências Ambientais e Sustentabilidade Agropecuária) - Universidade Católica Dom Bosco, Campo Grande, MS.

BOND, Emerson. Medição de desempenho para gestão de produção em um cenário para cadeia de suprimentos. 2002. 125f. Dissertação (Mestrado em Engenharia de Produção) - Universidade de São Paulo, São Carlos.

BRASIL. Lei $n^{\circ}$ 4.504, de 30 de novembro de 1964. Dispõe sobre o Estatuto da Terra, e dá outras providências. Disponível em: <http://www.planalto.gov.br/ccivil_03/ Leis/L4504.htm>. Acesso em: 16 ago. 2015.

Lei $n^{0}$ 11.638/07, de 28 de dezembro de 2007. Altera e revoga dispositivos da Lei $\mathrm{n}^{-} 6.404$, de 15 de dezembro de 1976, e da Lei no 6.385, de 7 de dezembro de 1976, e estende às sociedades de grande porte disposições relativas à elaboração e divulgação de demonstrações financeiras. Disponível em: <http:/ / www.planalto.gov.br/ccivil_03/_ato2007-2010/2007/ lei/111638.htm>. Acesso em: 16 ago. 2015.

COBRA, Marcos. Administração de marketing. 2.ed. São Paulo: Atlas, 1992.

CASSARO, Antonio Carlos. Sistemas de informações para tomada de decisões. 3. ed. São Paulo: Pioneira, 1999.

COMITÊ DE PRONUNCIAMENTOS CONTÁBEIS - CPC. Pronunciamento Técnico CPC 12, de 5 de dezembro de 2008. Ajuste a valor presente. Disponível em: <http://www.cpc.org.br/ CPC/Documentos-Emitidos/Pronunciamentos/ Pronunciamento?Id=43>. Acesso em: 15 ago. 2015.

Pronunciamento Técnico CPC 29, de 07 de agosto de 2009. Ativo biológico e produto agrícola. Correlação às Normas Internacionais de Contabilidade - IAS 41. Disponível em: <http://www.cpc.org. br/CPC/Documentos-Emitidos/Pronunciamentos/ Pronunciamento?Id=60>. Acesso em: 3 maio 2015. Pronunciamento Técnico CPC 46, de 7 de dezembro de 2012. Mensuração do valor justo. Correlação às Normas Internacionais de Contabilidade - IFRS 13. Disponível em: <http://www.cpc.org. br/CPC/Documentos-Emitidos/Pronunciamentos/ Pronunciamento?Id=78>. Acesso em: 25 nov. 2015.
COSIF. Norma Brasileira de Contabilidade do Conselho Federal de contabilidade. NBC TG 1000, [s.d.]. Disponível em: <http://cosif.com.br/publica. asp?arquivo=padron2>. Acesso em: 16 ago. 2015.

COMISSÃO do século XXI - sistemas de agricultura. Relatório Técnico. Conselho Nacional de Pesquisa. Rumo a sistemas de agricultura sustentável no século 21. Washington: The National Academies Press, 2010.

COMPANHIA NACIONAL DE ABASTECIMENTO CONAB, 2012. Disponível em: <http://www.conab. gov.br/>. Acesso em: 17 ago. 2015.

CREPALDI, Silvio Aparecido. Contabilidade Gerencial teoria e prática. São Paulo: Atlas, 2006.

DOWLING, C.; GODFREY, J. AASB 1037 sows the seeds of change: a survey of SGARA measurement methods. Australian Accounting Review, Sidney, v. 11, n. 1, p. 4551, mar. 2001.

ERNEST\&YOUNG; FIPECAFI. Manual de normas internacionais de contabilidade: IFRS versus normas brasileiras. São Paulo: Atlas, 2010.

FELEAGÃ, Liliana; FELEAGÃ, Niculae; RÃILEANU, Vasile. IAS 41 implementation challenges: the case of Romania. World Academy of Science, Engineering and Technology. International Journal of Social, Management, Economics and Business Engineering, v. 6, n. 3, 2012. Disponível em: <http:/ / waset.org/publications /2508/ ias-41-implementation-challenges-the-case-of-romania>. Acesso em: 12 maio 2015.

FRANCO, Hilário. Contabilidade geral. 23. ed. São Paulo: Atlas, 1999.

HARRINGTON, James. Gerenciamento total da melhoria contínua. São Paulo: Makron Books, 1997.

HERBOHN, K.; HERBOHN, J. International Accounting Standard (IAS) 41: What are the Implications for Reporting Forest Assets? Small-scale Forest Economics, Management and Policy, Austrália, v. 5, n. 2, p. 175-189, 2006.

HENDRIKSEN, Eldon S.; VAN BREDA, Michael F. Teoria da contabilidade. São Paulo: Atlas, 1999.

INSTITUTO DOS AUDITORES INDEPENDENTES DO BRASIL - IBRACON, 2009. Disponível em: <http:// www.ibracon.com.br/ibracon/Portugues/>. Acesso em: 17 ago. 2015.

INSTITUTO BRASILEIRO DE GEOGRAFIA E ESTATÍSTICA - IBGE, 2013. Disponível em: <http:/ / www. ibge.gov.br/home/>. Acesso em: 14 ago.2015.

IUDÍCIBUS, Sérgio. Teoria da contabilidade. São Paulo: Atlas, 2000.

Teoria da contabilidade. São Paulo: Atlas, 2004.

LISBOA, Lázaro Plácido; SCHERER, Luciano Márcio. Fair value accounting e suas implicações nas atividades agropecuárias. Revista Brasileira de Contabilidade, Brasília, ano XXIV, n. 126, p. 66-83, nov./dez. 2000.

MINISTÉRIO DA AGRICULTURA PECUÁRIA E ABASTECIMENTO - MAPA, 2013. Disponível em: <http://www.agricultura.gov.br/>. Acesso em: 16 ago. 2015.

MARION, José Carlos. Contabilidade rural. 7. ed. São Paulo: Atlas, 2002. 
. Contabilidade rural, 13. ed. São Paulo: Atlas, 2012.

MIRANDA, Luiz Carlos.; SILVA, José Dionisio Gomes da. Medição de desempenho. In: SCHMIDT, P. (Org.). Controladoria: agregando valor para a empresa. Porto Alegre: Bookman, 2002.

NIYAMA, Jorge Katsumi; SILVA, César Augusto Tibúrcio. Teoria da contabilidade. São Paulo: Atlas, 2008.

NOGUEIRAS, Maurício Palma. Leite: queda nos preços continua. Balde branco, nov. 2014. Disponível em: <http:/ / www.baldebranco.com.br/layout/quedacontinua. html>. Acesso em: 17 ago. 2015.

PORTER, Michael. Vantagem competitiva: criando e sustentando um desempenho superior. 15. ed. Rio de Janeiro: Campus, 1989.

RECH, Ilírio José. Formação do valor justo dos ativos biológicos sem mercado ativo: uma análise baseada no valor presente. 2011. 190 f. Tese (Doutorado em Ciências Contábeis) - Universidade de São Paulo. São Paulo. Disponível em: <http://www.teses.usp.br/teses/disponiveis/12/12136/tde-19032012-185759/pt-br.php>. Acesso em: 10 mai. 2015.

RECH, Ilírio José; PEREIRA, C.; PEREIRA, I.; CUNHA, M. IAS 41 - Agriculture: um estudo da aplicação da norma internacional de contabilidade às empresas de pecuária de corte. In: CONGRESSO USP. CONTROLADORIA E CONTABILIDADE, 6., 27-28 jul. 2006. São Paulo. Anais... São Paulo: USP, 2006.

SAVITZ, Andrew W.; WEBER, Karl. A empresa sustentável: o verdadeiro sucesso é o lucro com responsabilidade social e ambiental. Tradução de Afonso Celso da Cunha Serra. Rio de Janeiro: Elsevier, 2007.

VIVIANI, Ana Elisa. Sustentabilidade nos negócios. Ciatech, 3 out. 2011. Disponível em: <http://blog.ciatech.com. br/2011/10/03/sustentabilidade-nos-negocios/ > . Acesso em: 14 mai. 2015.

WATTS, R. L. Conservatism in Accounting Part 1: Explanations and implications. Accounting Horizons, v. 17, n. 3, p. 207-221, set. 2003.

WORLD COMISSION ON ENVIRONMENT AND DEVELOPMENT - WCED. Our Commom Future. Oxford, New York: Oxford University Press, 1987.

YANG, Ziyun; ROHRBACH, Kermit; CHEN, Shimin. The impact of standard setting on relevance and reliability of accounting information: lower of cost or market accounting reforms in China. Journal of International Financial Management \& Accounting, v. 16, n. 3, p. 194-228, 2005. 